\title{
"UTUSLAH AKU": \\ EKSPOSISI YUNUS PASAL 3-4 TENTANG PENGUTUSAN NABI YUNUS BERDASARKAN PERSPEKTIF ALLAH MENYESAL
}

\author{
Peniel Maiaweng \\ sttjaffraymakassar@yahoo.co.id \\ Peniel_68@yahoo.co.id
}

\section{PENDAHULUAN}

Dalam Perjanjian Lama, pengutusan nabi yang ditegaskan dalam perkataan, "Siapakah yang akan Kuutus, dan siapakah yang mau pergi untuk Aku?" (6:8a), mengekspresikan pengesahan ilahi yang disertai dengan pemberian kuasa untuk misi yang dipercayakan kepada nabi, ${ }^{1}$ dan dalam melaksanakan tugasnya, nabi adalah wakil Allah yang berbicara atas nama Allah. Sedangkan, pernyataan nabi, "Ini aku, utuslah aku!" (Yes. 6:8b), menyatakan kesediaan dan kesungguhan nabi dalam menaati panggilan pelayanan, konsisten terhadap pengutusan yang diterimanya, setia dalam melaksanakan tanggung jawab yang dipercayakan kepadanya, dan siap untuk menerima segala bentuk konsekuensi yang dialami dalam pelayanannya, karena nabi memiliki keyakinan bahwa ia adalah utusan Allah dan otoritas pelayanan ada pada dirinya.

Pada kenyataannya, tidak semua nabi hidup sesuai dengan panggilan yang diterimanya, seperti halnya nabi Yunus. Pengutusan nabi Yunus dianggap sebagai pengutusan nabi yang paling fenomena karena ketidakkonsistensinya terhadap panggilan yang diterimanya. Dikatakan demikian, karena:

- Tidak ada nabi dalam Perjanjian Lama yang melarikan diri dari panggilannya sebagai nabi, selain nabi Yunus (1:3).

- Yunus adalah nabi yang melarikan diri ke Tarsis, tetapi dalam pelariannya menuju Tarsis, para awak kapal yang mengalami musibah bersamanya, percaya kepada Allah, mempersembahkan korban, dan mengikrarkan nazar (1:16). Dengan perkataan lain, Yunus melarikan diri dari panggilannya dan tidak menginjili (dalam konteks PL), tetapi sudah ada petobat baru.

- Semua karakter dalam kitab Yunus, seperti angin ribut (1:4), ikan besar (1:17; 2:10), orang-orang Niniwe dan ternak-ternaknya (3:5-8);

\footnotetext{
"“How the Soveregin LORD God Prepares His Servants Isaiah 6:1-13" oleh Allen Ross, tersedia di http://www.bible.org/seriespage/how-sovereign-lod-god-prepareshis-servants-isaiah-61-13 diakses pada tanggal 8 Januari 2012.
} 
pohon jarak, ulat, dan angin timur (4:6-8), hanya membutuhkan satu kali perintah atau penentuan; tetapi Yunus membutuhkan dua kali panggilan (1:2; 3:2).

- Yunus adalah nabi yang berita nubuatannya paling sedikit (hanya terdapat dalam 3:4), tetapi telah menghasilkan pertobatan orangorang di Niniwe yang jumlahnya lebih dari seratus dua puluh ribu (4:11).

- Yunus adalah nabi yang merasakan hasil pelayanannya secara langsung, yaitu pertobatan secara besar-besaran di Niniwe (3:5-9), tetapi ia adalah nabi yang marah kepada Allah karena keberhasilan dalam pengutusannya ke Niniwe (4:1-3).

- Yunus adalah nabi yang meminta kepada TUHAN untuk mencabut nyawanya karena keberhasilannya dalam pelayanannya dan ia pun menginginkan kematiannya melalui kemarahannya (4:3, 8b, 9b).

Fenomena pengutusan nabi Yunus bermula dari ketidaksenangannya terhadap sifat-sifat dan sikap Allah yang dinyatakan kepada bangsa-bangsa yang bukan Israel dan yang memiliki kekuasaan secara politik atas Israel, secara khusus Niniwe. Hal ini diinformasikan dalam narasi kitab Yunus pasal 3-4.

Firman yang disampaikan Yunus di Niniwe (3:4) menghasilkan pertobatan secara nasional (3:5-8). Puncak dari pertobatan, orang-orang di Niniwe berharap kepada Allah dengan berkata, "Siapa tahu, mungkin Allah ... menyesal ... sehingga kita tidak binasa” (3:9).

Allah pun berespon sesuai keberadaan-Nya yang menyesal, “... maka menyesallah Allah karena malapetaka yang telah dirancangkan-Nya terhadap mereka ..." (3:10).

Penyataan diri Allah yang menyesal terhadap Niniwe membuat Yunus marah kepada Allah. Hal ini dinyatakan Yunus melalui sikap dan doanya,

Tetapi hal itu sangat mengesalkan hati Yunus, lalu marahlah ia. Dan berdoalah ia kepada TUHAN, katanya: Ya TUHAN, bukankah telah kukatakan itu, ketika aku masih di negeriku? Itulah sebabnya, maka aku dahulu melarikan diri ke Tarsis, sebab aku tahu, bahwa Engkaulah Allah yang pengasih dan penyayang, yang panjang sabar dan berlimpah kasih setia serta yang menyesal karena malapetaka yang hendak didatangkan-Nya. Jadi sekarang, ya TUHAN, cabutlah kiranya nyawaku, karena lebih baik aku mati dari pada hidup (4:1-3).

Kemarahan Yunus menunjukkan bahwa, menurut Yunus, seharusnya Allah menggenapi firman yang telah disampaikannya tentang 
malapetaka yang akan dialami oleh Niniwe (3:4), tetapi yang terjadi adalah pertobatan orang-orang Niniwe (3:5-8) dan pembatalan malapetaka (3:10). Yunus menilai bahwa Allah tidak konsisten dengan firman yang telah disampaikannya, karena bagi Yunus, orang-orang Niniwe yang hidup dalam tingkah laku yang jahat dan kekerasan (3:8), seharusnya mengalami malapetaka, tetapi justeru diselamatkan oleh Allah (3:10). Yunus menganggap bahwa tidak ada gunanya menyatakan malapetaka di Niniwe, karena TUHAN menyesal akan malapetaka yang telah dirancangkan-Nya.

Keadaan ini membuat Yunus meminta TUHAN untuk mencabut nyawanya $(4: 3,8 b)$, bahkan Yunus berkata kepada TUHAN, "Selayaknyalah aku marah sampai mati" (3:9b). Yunus menilai dirinya bahwa ia pantas untuk marah hingga tiba ajalnya. Demikianlah permasalahan yang dihadapi oleh Yunus.

Untuk itu, pembahasan makalah difokuskan pada penjelasan makna (leksikal dan konteks), dilanjutkan dengan kajian teologis-biblis untuk memahami Allah yang menyesal sebagai Pengutus sejati, dan diakhiri dengan pembahasan tentang implikasi teologis-praktis sebagai masukan tentang tanggung jawab yang harus dimiliki oleh setiap hamba Tuhan sebagai orang yang diutus oleh Allah dalam melaksanakan pelayanan yang dipercayakan kepadanya. ${ }^{2}$

\footnotetext{
${ }^{2}$ Penyataan diri Allah yang menyesal telah menjadi perdebatan secara teologis oleh para teolog. Ada yang berpendapat bahwa Allah tidak mungkin menyesal (Louis Berkhof, Charles C. Ryrie, Millard J. Erickson, Paul E. Little) dan ada yang berpendapat bahwa Allah mungkin saja menyesal (A. Th. Kramer, Donald C. Stamps, Gregory A. Boyd, Richard Rice), dengan alasannya masing-masing, namun dalam orasi ilmiah ini, kajian tidak difokuskan pada penyelesaian perbedaan pandangan teologi yang ada, tetapi mengacu pada pengutusan nabi Yunus berdasarkan perspektif Allah yang menyesal.
} 


\section{MAKNA LEKSIKAL “ALLAH MENYESAL”}

Kata "menyesal" dalam PL diterjemahkan dari kata dalam bahasa Ibrani nakham. Nakham adalah kata kerja yang awal penggunaannya mengekspresikan tindakan seseorang yang menarik napas panjang dan dalam, atau bernafas dengan kuat. ${ }^{3}$ Ekspresi ini hanya terjadi ketika seorangberada dalam keadaan sangat marah, sangat sedih, sangat lega, dan sangat puas. Dalam perkembangannya, nakham menyatakan pengekspresian hal-hal yang baik (memiliki belas kasih, merasa sayang,menghibur, dan menyenangkan) dan hal-hal yang buruk (menyatakan kemarahan, membalas dendam, atau melepaskan dendam). Nakham juga menyatakan perubahan sikap dan pikiran seseorang dari apa yang telah direncanakan sebelumnya, yaitu dari yang buruk menjadi baik, atau dari yang baik menjadi buruk, ${ }^{4}$ sebagai wujud kekesalan, kemarahan, dan kepuasan diri. berarti:

Dalam Perjanjian Lama, penyataan diri Allah sebagai Allah menyesal

1. Allah berinisiatif untuk menyatakan hukuman kepada manusia karena dosanya (bdg. Kej. 6:5-7; Yun. 3:4, 10).

2. Allah berinisiatif membatalkan malapetaka yang telah dirancangkanNya karena permohonan dan pertobatan manusia (bdg. Kel. 32:12; Yun. 3:10).

3. Allahberbelas kasih kepada orang-orang yang merintih karena didesak dan ditindas (bdg. Hakim 2:18).

4. Allah merasa saying kepada umat-Nya (bdg. Mzr. 90:13).

5. Allah memberikan penghiburan kepada umat-Nya (bdg. Yeh. 14:22).

6. Allah mengadakan pembalasan terhadap musuh-musuh-Nya (bdg. Yes. $1: 24)$.

Dengan demikian, menyesal (nakham) yang ada pada diri Allah menyatakan sikap dan perasaan Allah yang diekspresikan kepada manusia ketika berhadapan dengan manusia yang berdosa, bertobat, berduka, tertindas, yang pada satu sisi bersifat negatif, berupa murka,

${ }^{3}$ James Strong, Strong's Exhaustive Concordance of the Bible, Reference Library Edition. (Iowa Falls, Iowa: World Bible Publishers, n.d), s.v. "nacham."Nakham adalah kata kerja nifal (pasif), namun nakham tidak memiliki bentuk aktif jadi selalu diterjemahkan dalam bentuk aktif.

${ }^{4}$ Ibid. 
penghukuman, pembalasan, dan malapetaka, dan pada sisi yang lain bersifat positif, berupa belas kasih, keselamatan, penghiburan, dan pembelaan, sebagai tindakan-Nya yang tepat bagi manusia.

\section{MAKNA KONTEKS “ALLAH MENYESAL”}

Dengan memahami narasi kitab Yunus pasal 3-4, maka dapat ditentukan pengertian Allah menyesal berdasarkan konteks.

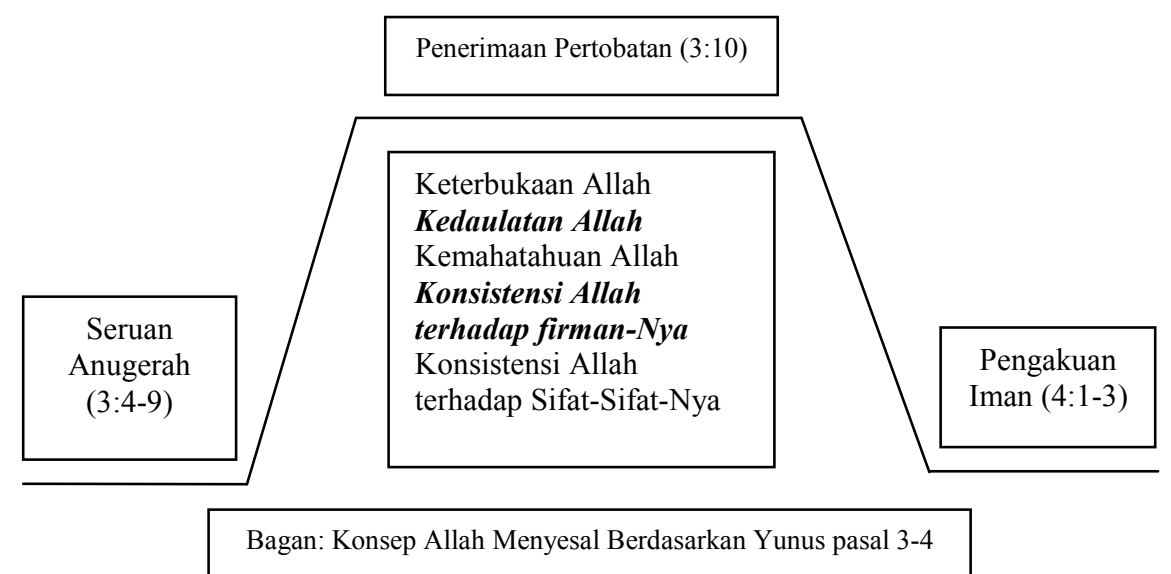

Allah yang Menyesal adalah Allah yang Menyerukan Anugerah (3:4)

Firman yang disampaikan Yunus, "Empat puluh hari lagi, maka Niniwe akan ditunggangbalikkan (nehpaket)" (3:4), tidak hanya berarti Niniwe akan dibinasakan, ${ }^{5}$ tetapi juga berarti diubahkan. ${ }^{6}$ Dengan maksud, Niniwe akan ditunggangbalikkan atau akan ditransformasi untuk menjadi lebih baik bergantung pada respon orang-orang yang berada di kota Niniwe. ${ }^{7}$ Ini menunjukkan bahwa nubuat yang disampaikan Yunus tidak selamanya memiliki konsekuensi negatif.

\footnotetext{
${ }^{5}$ Ibid, s.v." hapakh". Bentuk nifal (pasif) adalah nehpaket berarti dibinasakan atau ditunggangbalikkan.

${ }^{6}$ Dalam bentuk nifal (nehpaket) berarti mengubah seseorang, dan digunakan untuk menandakan perubahan yang radikal dari sesuatu yang ekstrim kepada yang lain, termasuk perubahan sikap hati dan pikiran. Thomas M. Bolin, Freedom Beyond Forgiveness: The Book of Jonah Re-Examined (Sheffield: Sheffield Academic Press, 1997), 125.

${ }^{7}$ Alan Cooper, "In Praise of Divine Caprice: The Significant of the Book of Jonah," ini Philip R. Davies and David J. A. Clines (Editors), Among The Prophets: Language, Image and Structure in the Prophetic Writings. Journal for the Study of the Old Testament Suplement Series (Sheffield: Shiffield Academic Press, 1993), 145.
} 
Dengan demikian, seruan malapetaka, "empat puluh hari lagi, maka Niniwe akan ditunggangbalikkan," bukanlah suatu keputusan (decree) yang tidak dapat dibatalkan oleh Allah sesuai dengan yang telah dinyatakan, ${ }^{8}$ tetapi sebagai seruan (announcement) yang menyatakan anugerah Allah kepada orang-orang Niniwe. ${ }^{9}$ Dengan maksud, empat puluh hari adalah kesempatan yang diberikan Allah kepada orang-orang Niniwe untuk berbalik dari tingkah lakunya yang jahat. Buktinya, ada pertobatan orang-orang Niniwe dalam masa empat puluh hari (3:5-8) sehingga Allah menyesal akan malapetaka yang telah dirancangkan-Nya dan Ia tidak menghukum Niniwe (3:10).

\section{Allah yang Menyesal adalah Allah yang Menerima Pertobatan (Yunus 3:10)}

Pemberitaan Yunus di Niniwe menghasilkan pertobatan orangorang Niniwe dan Allah menyatakan sikap-Nya yang menyesal. Wujud pertobatan orang-orang Niniwe adalah:

- Ketika orang-orang Niniwe mendengar firman tentang malapetaka (3:4), mereka percaya kepada Allah dan berpuasa (3:5).

- Ketika berita itu sampai kepada raja, ia turun dari takhtanya, menanggalkan jubahnya, mengenakan kain kabung, dan duduk di abu (3:6). Tindakan raja melebihi tindakan rakyatnya.

- Para pembesar mengumumkan perkabungan dan pertobatan secara nasional yang harus dilakukan oleh seluruh rakyat (3:7-8).

Ekspresi orang-orang Niniwe demikian menyatakan rasa duka yang mendalam. Ekspresi ini biasanya hanya dilakukan apabila salah satu anggota keluarga mereka meninggal, ${ }^{10}$ tetapi hal ini mereka lakukan ketika mereka mendengar malapetaka yang akan menimpa mereka.

Allah berespon terhadap pertobatan dan perkabungan orang-orang di Niniwe. Respon Allah dimulai dari Allah menilai pertobatan orangorang Niniwe.

- Penilaian Allah diekspresikan dalam kalimat, "Ketika Allah melihat perbuatan mereka itu, yakni bagaimana mereka berbalik dari tingkah

\footnotetext{
${ }^{8}$ Ayat-ayat yang berhubungan dengan keputusan adalah Bil. 23:19; I Sam. 15:29, Mzr. 110:4; Yer. 4:28; Yeh. 24:14; Zak. 8:14. Robert B. Chisholm, "Does God Change His Mind?" Bibliotheca Sacra 152 (October-Desember 1995): 391-396.

${ }^{9}$ Ayat-ayat yang berhubungan dengan proklamasi diri Allah sebagai Allah yang menyesal adalah Keluaran 32:12, 14 (Amos 7:3, 6); Yeremia 15:6 (18:8, 10; 26:3, 13, 19); Yoel 2:13-14; Yunus 3:9 (3:10; 4:2). Ibid, 396-399.

${ }^{10}$ C. F. Keil, "Twelve Minor Prophet" volume 1 in C. F. Keil and F. Delitzsch, Biblical Commentary on The Old Testament (Grand Rapids, Michigan: Wm. B. Eerdmans Publishing Company, 1965), 408.
} 
lakunya yang jahat ..." (3:10). Kata melihat (ra'a) memiliki makna menilai secara benar berdasarkan pengamatan yang cermat dan teliti, dengan maksud, melihat adalah tindakan Allah yang bukan asalasalan dalam menilai pertobatan orang-orang Niniwe. ${ }^{11}$

- Hasil penilaian Allah adalah bahwa orang-orang di Niniwe tidak hanya sekadar menyesal, tetapi mereka juga benar-benar telah berbalik dari cara hidup yang jahat, baik secara lahiriah maupun batiniah.

- Berdasarkan penilaian tersebut, Allah membatalkan malapetaka atas Niniwe, “... maka menyesallah Allah karena malapetaka yang telah dirancangkan-Nya terhadap mereka, dan Ia pun tidak jadi melakukannya" (3:10). Allah tidak menunggangbalikkan Niniwe karena orang-orang Niniwe telah bertobat.

Narasi ini menunjukkan bahwa firman yang disampaikan Yunus bukanlah firman yang mematikan, tetapi firman yang menimbulkan kesadaran orang-orang Niniwe untuk berbalik dari tingkah lakunya yang jahat sehingga Allah membatalkan malapetaka yang seharusnya ditimpakan kepada mereka. ${ }^{12}$ Dengan demikian, Allah menyesal akan malapetaka yang telah dirancangkan-Nya atas Niniwe adalah bukti bahwa Allah menerima pertobatan orang-orang Niniwe.

\section{Allah yang Menyesal adalah Pengakuan Iman (4:2)}

Keberadaan Allah yang disebut Yunusdalam doanya adalah, “... Engkaulah Allah yang pengasih dan penyayang, yang panjang sabar dan berlimpah kasih setia serta yang menyesal karena malapetaka yang hendak didatangkan-Nya" (4:2), adalah penyebutan menunjukkan bahwa Yunus mengakui keberadaan Allah yang menyesal sebagai bagian dari diri Allah.

Sejarah pengakuan ini didasarkan pengikatan perjanjian yang telah dilakukan oleh TUHANdengan bangsa Israel di gunung Sinai. Ketika Allah akan menghukum bangsa Israel karena penyembahan terhadap anak lembu tuangan, Musa bersyafaat kepada Allah dengan berkata, "Berbaliklah dari murka-Mu yang bernyala-nyala itu dan menyesallah karena malapelaka yang hendak Kaudatangkan kepada umat-Mu" (Kel. 32:12b),

\footnotetext{
${ }^{11}$ Bandingkan penggunaan kata ra'a dalam penciptaan, yang mana Allah melihat (ra'a) segala yang dijadikan-Nya sungguh amat baik (Kej. 1:31).

${ }^{12}$ Kramer menyebutkan bahwa firman yang disampaikan Yunus telah menghasilkan jalan baru bagi orang-orang Niniwe. A. Th. Kramer, Tafsiran Alkitab: Kitab Yunus (Jakartga: BPK Gunung Mulia, 1990), 46.
} 
dan Allah berespon sesuai dengan syafaat yang disampaikan Musa, "Dan menyesallah TUHAN karena malapetaka yang dirancangkan-Nya atas umat-Nya" (Kel. 32:14). ${ }^{13}$

Berdasarkan pengalaman tersebut, para nabi menambahkannya dalam daftar penyebutan sifat dan sikap Allah ketika para nabi berbicara kepada Israel yang hidup dalam dosa, penyembahan berhala, dan nyaris dihukum oleh Allah. ${ }^{14}$ Hal ini dibuktikan dengan penggunaannya dalam Perjanjian Lama yang dilakukan oleh nabi Yoel dan nabi Yunus.

'Tetapi sekarang juga,' demikianlah firman TUHAN, 'berbaliklah kepada-Ku dengan segenap hatimu, dengan berpuasa, dengan menangis dan dengan mengaduh. Koyakkanlah hatimu dan jangan pakaianmu, berbaliklah kepada TUHAN, Allahmu, sebab Ia pengasih dan penyayang, panjang sabar dan berlimpah kasih setia, dan Ia menyesal karena hukuman-Nya. Siapa tahu, mungkin Ia mau berbalik dan menyesal, dan ditinggalkan-Nya berkat, menjadi korban sajian dan korban curahan bagi TUHAN, Allahmu.' (Yoel 2:12-14).

... Engkaulah Allah yang pengasih dan penyayang, yang panjang sabar dan berlimpah kasih setia serta yang menyesal karena malapetaka yang hendak didatangkan-Nya (Yunus 4:2).

Penyebutan demikian menunjukkan bahwa keberadaan Allah yang menyesal diakui oleh para nabi dan orang Israel sebagai bagian dari diri Allah, sehingga walaupun Yunusberada dalam keadaan marah, namun Yunusmengetahui secara benar bahwa Allah yang mengutusnya adalah Allah yang menyesal akan malapetaka yang telah dirancangkan-Nya. ${ }^{15}$ Pengakuan tersebut tidak hanya disampaikan oleh para nabi, tetapi juga disebutkan dalam konteks pengajaran dan penyembahan orang-orang Israel. ${ }^{16}$ Dengan demikian dalam Perjanjian Lama, Allah tidak hanyadiakui dan disembah karena keberadaan-Nya yang pengasih, penyayang, panjang sabar dan berlimpah kasih setia, tetapi jugayang menyesal akan malapetaka yang dirancangkan-Nya.

\footnotetext{
${ }^{13}$ Steven C. Roy, How Much Does God Foreknow? A Comprehensive Biblical Study (Downers Groves, Illinois: InterVarsity Press, 2006), 14l. Setelah peristiwa tersebut, penyebutan, Allah menyesal, menjadi bagian penyebutan tentang sikap Allah yang dirangkaikan dengan sifat-sifat Allah (pengasih, penyayang, panjang sabar, dan berlimpah kasih setia).

${ }^{14}$ Ibid.

${ }^{15}$ Ibid., 143.

${ }^{16}$ Joyce Baldwin, "Jonah" in Thomas Edward McComiskey (editor), An Exegetical $\diamond$ Expository Commentary Volume Two (Grand Rapids, Michigan: Baker Book House, 1993), 583.
} 


\section{KAJIAN TEOLOGIS-BIBLIKA}

Berdasarkan pengalaman Nabi Yunus dalam pengutusannya yang kontroversi ke Niniwe, terdapat kajian teologis untuk membuktikan bahwa Allah yang menyesal adalah Allah yang bertanggung jawab terhadap pengutusan nabi-Nya dan Niniwe yang menjadi fokus pengutusan Yunus.

\section{Allah yang Menyesal adalah Allah yang Terbuka}

Dengan adanya pengutusan Yunus ke Niniwe (1:2; 3:2), kehadiran Yunus di Niniwe (3:3), dan firman yang disampaikannya (3:4) sehingga membuat orang-orang di Niniwe mengharapkan Allah menyesal (3:9), menunjukkan bahwa Allah terbuka bagi bangsa-bangsa lain. Sikap Allah yang menyesal menjadi kritik bangsa Israel yang tidak mengasihi bangsabangsa yang berada di sekitarnya ${ }^{17}$ tetapi telah menjadi jalan masuk bagi orang-orang Niniwe untuk memperoleh keselamatan dari malapetaka. Ini berarti bahwa walaupun orang Niniwe bukanlah umat pilihan Allah dan tidak ada nabi yang lahir dari bangsa ini, tetapi Allah telah menyatakan anugerah-Nya kepada mereka melalui nabi Yunus yang menjadi dasar bagi mereka untuk memperbaiki tingkah lakunya.

Hal ini sejalan dengan yang dimaksud oleh Vinay Samuel dan Chris Sugden, bahwa dalam Perjanjian Lama, Allah tidak hanya bekerja di antara umat-Nya, tetapi juga di antara bangsa lain. Allah tidak hanya memprakarsai sejarah kehidupan Israel, tetapi juga memprakarsai kehidupan bangsa-bangsa lain (Amos 9:7). Pengontrolan Allah atas Israel secara mendasar tidak berbeda dengan pengontrolan-Nya atas bangsa-bangsa lain. Ke-Tuhan-an Allah tidak hanya berlaku bagi bangsa Israel, tetapi juga berlaku bagi bangsa-bangsa lain. ${ }^{19}$

Dengan demikian, Allah yang menyesal adalah Allah yang tidak hanya terikat kepada bangsa Israel dan tidak membatasi diri-Nya hanya kepada orang tertentu atau bangsa tertentu. Pengutusan Yunus ke Niniwe, penyataan anugerah, dan pembatalan malapetaka, membuktikan

\footnotetext{
${ }^{17}$ Robert D. Recker, "The Biblical Mandate," in Harvie M. Conn (Editor), Reaching the Unreached: The Old-New Challenge (New Jersey: Presbyterian and Reformed Publishing Company, 1984), 3.

${ }^{18}$ C. Barth, Teologi Perjanjian Lama 4 (Jakarta: BPK Gunung Mulia, 1993), 125.

${ }^{19}$ Vinay Samuel and Chris Sugden, "God's Intention for the World: Tensions between Eschatology and History," in Tom Sine (Editor), The Church In Respon to Human Need (Wheaton: Missions Advanced Research and Communication Center, 1983), 182.
} 
bahwa Allah membuka diri kepada bangsa lain agar mereka pun diselamatkan (bdg. Yer 18:7-8).

\section{Allah yang Menyesal adalah Allah yang Berdaulat}

Allah menyesal akan malapetaka yang telah dirancangkan-Nya atas Niniwe dan tidak melakukannya (Yun 3:10) menyatakan kedaulatan-Nya atas Niniwe. Dalam konteks kitab Yunus, kedaulatan Allah ditandai dengan inisiatif Allah terhadap Niniwe dan Yunus. Allah berinisiatif untuk menyelamatkan Niniwe sehingga Niniwe menjadi fokus penyelamatan. Allah berinisiatif untuk mengutus Yunus ke Niniwe (1:12). Allah berinisiatif untuk memberikan musibah di laut sebagai cara untuk membawa Yunus dari pelariannya (1:4). Allah berinisiatif menyelamatkan Yunus di laut dengan menentukan seekor ikan besar yang menelannya (1:17). Allah berinisiatif untuk membawa Yunus darat (2:10). Allah berinisiatif memberikan panggilan kedua kepada Yunus (3:1-2). Dan Allah berdaulat untuk menerima pertobatan orang-orang Niniwe sehingga Niniwe diselamatkan $(3: 5-9,10)$.

Kedaulatan Allah dalam menyelamatkan Niniwe menyangkut tiga aspek. Pertama. "Kendatipun tindakan Niniwe yang berusaha untuk menyelamatkan diri sendiri tidaklah memadai bilamana diukur berdasarkan standar Allah untuk menjamin kelepasan mereka. Allah sangat menghargai langkah sekecil apa pun ke arah yang benar dan Ia menunda pelaksanaan hukuman yang sudah diumumkan." ${ }^{20}$ Ini berarti bahwa pembatalan malapetaka yang dialami oleh orang-orang Niniwe, bukan didasarkan pada kebaikan diri mereka, tetapi karena malapetaka yang dirancangkan Allah menghasilkan pertobatan pada orang-orang Niniwe, dan Allah menerima pertobatan mereka.

Kedua. Sikap Allah yang menyesal akan malapetaka yang dirancangkan atas Niniwe memiliki implikasi bahwa keselamatan bukanlah hadiah dari sebuah jasa kebaikan dan bukan pula suatu perubahan dari keadilan kepada kemurahan, tetapi kedaulatan Allah, agar orang-orang berdosa hanya mengharapkan keselamatan dari Allah. ${ }^{21}$

\footnotetext{
${ }^{20}$ Andrew E. Hill \& John H. Walton, Survey Perjanjian Lama (Gandum Mas, 1996), 637.

${ }^{21}$ Alan Cooper, "In Praise of Divine Caprice: The Significant of the Book of Jonah" in Philip R. Davies and David J. A. Clines, Among the Prophet: Language, Image and Structure in the Prophetic Writings, Journal for the Study of the Old Testament Supplement Series 144 (Sheffield: Sheffield Academic Press, 1993), 152.
} 
Ini berarti bahwa penerimaan pertobatan dan pembatalan malapetaka atas Niniwe adalah kedaulatan anugerah Allah untuk mengampuni dan menyelamatkan bangsa yang bukan umat pilihan Allah.

Ketiga. Sikap orang-orang Niniwe, "Siapa tahu, mungkin Allah akan berbalik dan menyesal..." menunjukkan kepasrahan merekahanya kepada kedaulatan Allah untuk memutuskan apa yang seharusnya Allah lakukan atas Niniwe. Walaupun orang-orang yang berada di kota Niniwe telah berbalik dari tingkah laku yang jahat, tetapi itu tidak menjamin keselamatannya, jika Allah tidak menyesal akan malapetaka yang telah dirancangkan-Nya. ${ }^{22}$ Ini menunjukkan bahwa kedaulatan sepenuhnya ada di tangan Allah untuk melakukan yang terbaik bagi Niniwe.

Dengan demikian, narasi kitab Yunus membuktikan bahwa Allah yang menyesal, bukanlah Allah yang menunjukkan keragu-raguan-Nya atau ketidakpastian akan sikap dan keputusan yang diambil-Nya, tetapi menyatakan kedaulatan-Nya yang mutlak atas manusia.

\section{Allah yang Menyesal adalah Allah yang Mahatahu}

Secara literal, menyesal (nakham) menunjukkan bahwa Allah dapat saja mengubah sikap menjadi marah atau murka untuk mengatasi kejahatan manusia yang semakin meningkat dan ketidaktaatan yang semakin menyolok, tetapi Allah juga dapat menyatakan kemurahan dalam hubungan dengan pertobatan manusia. ${ }^{23}$ Allah bertindak demikian karena Allah mengetahui segala situasi yang akan terjadi di waktu mendatang pada diri manusia dan Allah pun terbuka untuk berespon secara benar. ${ }^{24}$ Untuk itu, Allah menyesal akan malapetaka yang telah dirancangkan-Nya dan Ia pun tidak melakukannya, bukan karena Allah sulit mengambil keputusan yang tepat dan bukan pula Allah menyatakan sikap yang salah. ${ }^{25}$

Dalam konteks kitab Yunus, kematahuan Allah dibuktikan dengan Allah memprioritaskan Yunus ke Niniwe. Walaupun Yunus telah melarikan diri menuju ke Tarsis (1:3), tetapi Allah menimpakan badai besar di laut (1:4-15) dan Allah menentukan ikan besar untuk menelannya (1:17-2:9), sebagai cara untuk membawanya ke darat (2:10) untuk menyatakan panggilan kedua kepadanya (3:1-2).

\footnotetext{
${ }^{22}$ Baldwinin McComiskey (editor), 580.

${ }^{23}$ Bruce A. Ware, God's Lesser Glory: The Diminished God of Open Theism (Wheaton, Illinois: Crossway Books, 2000), 92.

${ }^{24}$ Ibid., 129.

${ }^{25}$ Bandingkan Charles Ryrie, Teologi Dasar, buku l (Yogyakarta: ANDI, 1992), 55.
} 
Setelah Yunus menerima panggilan kedua, ia memasuki kota Niniwe dan memberitakan malapetaka yang akan dialami oleh orangorang Niniwe (3:3-4). Respon orang-orang Niniwe adalah berbalik dari tingkah laku yang jahat dan kekerasan (3:5-8). Respon Allah terhadap orang-orang Niniwe adalah menyesal akan malapetaka yang telah dirancangkan-Nya (3:10). Respon orang-orang Niniwe dan Allah, menunjukkan bahwa keputusan Allah untuk memprioritaskan Yunus ke Niniwe adalah keputusan yang tepat (1:3, 4-15; 1:17-2:10; 3:1-2). Ini berarti bahwa, dengan memprioritaskan Yunus ke Niniwe, berarti Allah mengetahui apa yang akan terjadi di Niniwe dan tindakan apa yang harus dilakukan-Nya bagi Niniwe.

Dengan demikian, narasi kitab Yunus menunjukkan bahwa Allah yang menyesal akan malapetaka yang telah dirancangkan-Nya atas Niniwe adalah Allah yang mahatahu karena Ia telah bertindak secara tepat terhadap segala yang akan terjadi di Niniwe untuk kebaikan orang-orang Niniwe.

\section{Allah yang Menyesal adalah Allah yang Konsisten terhadap Firman- Nya}

Pertobatan Niniwe (Yun. 3:5-8) dan sikap Allah yang menyesal akan malapetaka yang telah dirancangkan-Nya menunjukkan bahwa Allah bertindak sesuai dengan firman-Nya. Berdasarkan konteks kitab Yunus, baik pemberitaan Yunus maupun pertobatan Niniwe, adalah cara yang digunakan oleh TUHAN untuk menyelamatkan Niniwe. Kehadiran Yunus adalah sebagai mediator Allah untuk menyatakan malapetaka yang akan membawa Niniwe kepada pertobatan. Dengan perkataan lain, Yunus tidak dapat menggagalkan rencara TUHAN untuk menyelamatkan Niniwe dan penetapan Yunus sebagai nabi untuk Niniwe tidak dapat dibatalkan dengan pelariannya ke Tarsis (1:3, 17; 2:10). Sikap Allah yang demikian menyatakan ketidakberubahan rencana-Nya, yang mana Niniwe tetap menjadi prioritas dan Yunus adalah nabi yang harus pergi ke Niniwe sebagai pembicara Allah.

Dengan demikian, berdasarkan narasi kitab Yunus, Allah yang menyesal bukanlah Allah tidak memiliki pendirian terhadap firman-Nya, tetapi menyatakan konsistensi Allah terhadap firman-Nya tentang Niniwe dan konsisten pilihan-Nya terhadap Yunus sebagai nabi bagi Niniwe. 


\section{Allah yang Menyesal adalah Allah yang Konsisten terhadap Sifat- Sifat-Nya}

Dalam kekesalan dan kemarahannya, Yunus berdoa dengan menyebutkan jati diti Allah,(4:2), “... Engkaulah Allah yang pengasih dan penyayang, yang panjang sabar dan berlimpah kasih setia serta yang menyesal karena malapetaka yang hendak didatangkan-Nya."

Isi doa tersebut terkandung kesesuaian sikap Allah yang menyesal dengan sifat-sifat yang dimiliki-Nya, dengan maksud:

1. Allah yang menyesal adalah Allah yang pengasih.

2. Allah yang menyesal adalah Allah yang penyayang.

3. Allah yang menyesal adalah Allah yang panjang sabar.

4. Allah yang menyesal adalah Allah yang berlimpah kasih setia.

Dengan demikian, sikap Allah yang menyesal yang dinyatakan kepada orang-orang Niniwe dalam bentuk pembatalan malapetaka bukan berarti bahwa Niniwe dapat melarikan diri dari malapetaka tersebut, tetapi karena Allah konsisten dengan sifat-sifat-Nya, yaitu pengasih, penyayang, panjang sabar, dan berlimpah kasih setia (4:2) yang menjadi dasar Allah membatalkan malapetaka yang telah dirancangkan-Nya (3:10).

\section{AKHIR KISAH PENGUTUSAN YUNUS}

Kitab Yunus seolah-olah menjadi sebuah kitab yang misteri karena diakhiri dengan sebuah pertanyaan retorika yang disampaikan Allah kepada Yunus,

Lalu Allah berfirman: "Engkau sayang kepada pohon jarak itu, yang untuknya sedikit pun engkau tidak berjerih payah dan yang tidak engkau tumbuhkan, yang tumbuh dalam satu malam dan binasa dalam satu malam pula. Bagaimana Aku tidak sayang kepada Niniwe, kota yang besar itu, yang berpenduduk lebih dari seratus dua puluh ribu orang, yang semuanya tidak tahu membedakan tangan kanan dari tangan kiri, dengan ternaknya yang banyak? $(4: 10-11)$

Namun dari pertanyaan tersebut membuktikan bahwa kitab ini diakhiri dengan sempurna. Apa yang menjadi pertanyaan dan penolakan Yunus terhadap TUHAN (1:3; 4:1-3), terjawab dalam 3:10 dan 4:11-12. Pada awalnya Yunus melarikan diri ke Tarsis karena ia tidak setuju dengan sifat-sifat dan sikap TUHAN yang dinyatakan kepada bangsabangsa lain (4:2). Tetapi proses penyadaran dengan menggunakan pohon jarak (4:6-7) dan diakhiri dengan penjelasan yang diberikan 
TUHAN tentang betapa pentingnya orang-orang di Niniwe (4:10-11), menunjukkan bahwa keraguan Yunus dalam 4:1-2 telah terjawab. Ini bukan berarti TUHAN mengabaikan Yunus sebagai nabi-Nya dan Israel sebagai umat pilihan-Nya, tetapi karena kebaikan-Nya kepada semua orang dan rahmat-Nya terhadap segala yang telah dijadikan-Nya. Rahmat TUHAN kepada Yunus dan Israel tidak mengurangi kasih-Nya kepada bangsa-bangsa lain. ${ }^{26}$ Dengan perkataan lain, jika TUHAN mengasihi Israel maka TUHAN juga mengasihi Niniwe.

Di akhir kitab Yunus, narator ingin menunjukkan bahwa pertanyaan retorika yang disampaikan TUHAN kepada Yunus membungkam Yunus. Yunus tidak dapat berbuat apa-apa karena ia sadar bahwa orang-orang Niniwe lebih berharga dari pohon jarak yang sedikit pun Yunus tidak berjerih payah dan Yunus pun tidak menumbuhkannya. Yunus hanya berdiam diri karena ia sadar bahwa orang-orang Niniwe dengan ternaknya yang banyak berada dalam kasih sayang Allah. Dengan demikian, pengutusan Yunus bukanlah pengutusan yang salah; sikap Allah yang menyesal akan malapetaka yang dirancangkan-Nya atas Niniwe bukanlah sikap yang salah; dan sikap Allah tidak menuruti permintaan Yunus untuk mencabut nyawanya bukanlah tindakan yang salah. Tindakan Allah demikian membuktikan bahwa Ia sangat mengasihi orang-orang Niniwe dan Ia pun sangat menghargai serta tetap mempertahankan Yunus sebagai nabi yang diutus-Nya ke Niniwe hingga akhir kitab Yunus.

\section{IMPLIKASI TEOLOGIS-PRAKTIS}

Berdasarkan pemahaman terhadap makna dan kajian teologisbiblis tentang Allah menyesal, maka dibangunlah implikasi teologispraktis, yang dalam makalah ini difokuskan kepada keberadaan hamba Tuhan $^{27}$ sebagai orang yang diutus oleh Allah.

\footnotetext{
${ }^{26}$ Beberapa bagian dari penjelasan ini terdapat dalam J. Sidlow Baxter, Menggali Isi Alkitab: Ayub s/d Maleakhi (Jakarta: Yayasan Komunikasi Bina Kasih, 1989), 384-385.

${ }^{27}$ Istilah "hamba Tuhan" dalam orasi ilmiah ini dikenakan kepada para alumni sebagai pengerja Kristen yang terpanggil melayani di gereja-gereja lokal, lembagalembaga Kristen, sekolah-sekolah (guru PAK), dan yayasan-yayasan yang bergerak dalam bidang pelayanan Kristen.
} 


\section{Eksistensi Hamba Tuhan}

Dalam Perjanjian Lama, Allah dapat melakukan apa saja bagi umat manusia untuk mendatangkan pertobatan dan keselamatan pada diri mereka, tetapi Ia juga memilih para nabi dan mengutus mereka untuk melaksanakan program penyelamatan-Nya bagi manusia. Pemilihan nabi merupakan gambaran keberadaan para hamba Tuhan sebagai orang yang diutus Allah, yang mana, sebagai seorang utusan Allah, hamba Tuhan adalah unik dan memiliki nilai serta potensi sehingga Allah memilihnya dan Allah tidak pernah memilih orang yang salah. Sebagai utusan Allah, ia adalah wakil Allah yang dilengkapi dengan kuasa dan wibawa ilahi serta menjadi orang kepercayaan Allah. Namun dalam pelayanan yang dilaksanakannya, ia adalah seorang yang mengabdikan dirinya dengan setia kepada Raja semesta alam (bdg. Yes. 6:3, 8b).

Sebutan-sebutan tersebut menunjukkan tanggung jawab besar yang harus diembannya, namun pada sisi lain, sebutan-sebutan tersebut adalah predikat ilahi yang dikenakan Allah pada dirinya. Untuk itu, setiap hamba Tuhan harus bangga dalam keberadaannya sebagai utusan, wakil, dan abdi Allah, bukan merasa terhina dengan sebutan-sebutan tersebut.

\section{Kecenderungan Pemuasan Diri}

Yunus adalah pribadi yang melayani sebagai nabi, tetapi ia ingin membatasi kasih sayang Allah hanya terfokus kepada dirinya dan bangsanya. Yunus menginginkan Allah mengikuti keinginan dirinya untuk tidak pergi ke Niniwe dari pada keinginan Allah untuk menyelamatkan Niniwe. Yunus merasa sayang kepada pohon jarak yang tidak ditanaminya, tetapi tidak merasa sayang kepada orang-orang Niniwe yang menjadi obyek pelayanannya. Yunus menyadari sifat-sifat Allah (pengasih, penyayang, panjang sabar, dan berlimpah kasih setia, serta yang menyesal akan malapetaka yang dirancangkan-Nya) dalam hidupnya, tetapi ia menginginkan sifat-sifat itu dinyatakan hanya kepada dirinya dan bangsanya.

Pengalaman Yunus menunjukkan bahwa seorang hamba Tuhan dapat saja memiliki pengetahuan dan pengakuan tentang Allah adalah kasih, tetapi ia cenderung menentukan bahwa kasih Allah yang dinyatakan Allah kepada manusia difokuskan hanya dalam konteks dirinya sendiri atau kelompoknya, bukan diperuntukkan juga bagi orang lain. Akibatnya adalah bahwa ia akan merasa cemburu, marah, dan kesal apabila Allah mengasihi dan memberkati orang lain sama dengan atau melebihi dari yang dialaminya, seperti Yunus marah kepada TUHAN yang menyesal akan malapetaka yang dirancangkan-Nya atas Niniwe. 
Pengalaman Yunus juga menunjukkan bahwa seorang hamba Tuhan dapat lebih mencintai berkat yang Allah berikan kepadanya dari pada melaksanakan tanggung jawab pelayanan yang dipercayakan kepadanya secara tulus, seperti Yunus yang bahagia terhadap pohon jarak yang menudungi tubuhnya, tetapi ia tidak memiliki kasih sayang terhadap orang-orang Niniwe. Konsekuensinya, setiap kali ia melayani, fokusnya adalah pemuasan diri sendiri dari pada memuliakan Allah dan menjadi berkat bagi orang-orang yang dilayaninya.

Jika seorang hamba Tuhan hidup dan melayani dengan cara demikian, maka ia tidak akan tahan menghadapi masalah serta kesulitan dalam pelayanannya dan ia akan selalu mengalami kekecewaan jika segala sesuatu yang menjadi pemuasan diri tidak terpenuhi. Hamba Tuhan yang cara hidupnya demikian cenderung akan menjadi hamba Tuhan yang pasif dan apatis, karena hanya akan menunggu apa yang akan terjadi, seperti Yunus yang pergi ke bagian timur kota Niniwe untuk melihat apa yang akan terjadi bagi Niniwe padahal Allah telah menyelamatkan Niniwe. Pada akhirnya, ia akan menjadi hamba Tuhan yang tidak konsisten dengan pengutusannya yang bermula pada panggilan dan komitmen awal, karena orientasinya bukan pada apa yang Allah ingin penuhi melalui hidupnya, tetapi pada apa yang menjadi pemuasan dirinya yang dipenuhi oleh Allah. Untuk itu, setiap hamba Tuhan harus mawas diri agar orientasi dan motivasi pelayanannya tidak terfokus pada pemuasan diri sendiri.

\section{Pemulihan Panggilan}

Yunus tidak setuju dengan panggilan Allah baginya ke Niniwe sehingga ia melarikan diri ke Tarsis (1:3), namun pelariannya bukan berarti ia kehilangan panggilannya sebagai nabi. Penyataan diri Allah sebagai Allah yang menyesal memungkinkan Yunus dipanggil kembali ke Niniwe. Allah tidak langsung menghukum Yunus karena pelariannya ke Niniwe, tetapi Allah menyadarkannya melalui peristiwa di laut (1:4-15), penyataan panggilan kedua (3:1-2), dan penyadaran tentang betapa berharga panggilan yang diterimanya untuk orang-orang di Niniwe.

Pengalaman Yunus menjadi pengajaran bagi hamba Tuhan bahwa kegagalan-kegagalan dalam bentuk apa pun yang dialami oleh seorang hamba Tuhan yang berhubungan dengan pelayanannya, tidak berarti ia kehilangan panggilan pelayanannya. Allah tetap konsisten dengan panggilan yang telah dinyatakan kepadanya dan Allah pun terbuka untuk menerimanya kembali. 
Sikap Allah demikian harus dipahami secara benar oleh setiap hamba Tuhan. Apabila seorang hamba Tuhan mengalami kegagalan secara rohani dalam pelayanan yang dilaksanakannya, janganlah ia tenggelam dalam kegagalan tersebut, tetapi bangkit dan datang kepada Tuhan untuk menyelesaikannya agar memperoleh pengampunan dan pemulihan untuk kembali kepada panggilan yang pernah dinyatakan kepadanya.

\section{Tergerak oleh Belas Kasih}

Allah menyesal (nakham) memiliki makna Allah tergerak oleh belas kasihan-Nya. ${ }^{28}$ Karena tergerak oleh belas kasihan, Allah menetapkan Yunus untuk Niniwe dan Niniwe menjadi fokus penyelamatan. Sikap Allah yang tergerak oleh belas kasih dalam Perjanjian Lama sejalan dengan sikap yang dimiliki Yesus dalam kitab-kitab Injil. Yesus tergerak hati-Nya oleh belas kasihan,

- Ketika Ia melihat banyak orang yang terlantar seperti domba yang tidak bergembala (Mat. 9:36).

- Ketika Ia melihat banyak orang sakit yang membutuhkan kesembuhan (Mat. 14:14)

- Ketika Ia melihat orang-orang yang mengikuti-Nya tetapi lapar karena tidak memiliki makanan (Mat. 15:32)

- Ketika Ia mengajarkan tentang pangampunan (Mat. 18:27)

- Ketika Ia mengajarkan tentang mengasihi sesama (Luk. 10:33).

Tergerak oleh belas kasihan adalah sikap mengasihi yang digerakkan oleh seluruh keberadaannya, yang mana rasa belas kasih dan haru yang mendalam dinyatakan seutuhnya terhadap orang yang menjadi obyek belas kasih, yang terwujud dalam tindakan yang nyata, termasuk berkorban dari apa yang dimilikinya. Dengan menghidupi sikap "tergerak oleh belas kasih," maka hamba Tuhan akan digerakkan untuk melakukan yang terbaik bagi orang-orang yang dilayani, bahkan siap melayani di antara orang-orang yang dianggap tidak baik dan di tempat yang dinilai tidak baik, untuk memenuhi kebutuhan rohani (bdg. Mat. 9:36), fisik (bdg. Mat. 14:14; 15:32), dan sosial (bdg. Mat. 18:27; Luk. 10:33) orang-orang yang dilayani.

\section{Pelaksanaan Penginjilan}

Pengutusan Yunus ke Niniwe menunjukkan bahwa Allah yang menyesal adalah Allah yang terbuka terhadap bangsa-bangsa yang bukan Yahudi dan Yunus adalah yang nabi yang dipercayakan untuk

\footnotetext{
${ }^{28}$ Anthony A. Heokema, Diselamatkan oleh Anugerah (Surabaya: Momentum, 2010), 162.
} 
memproklamasikan anugerah kepada orang-orang di Niniwe. Melalui pelayanan nabi Yunus, Allah menyatakan kasih-Nya kepada orang-orang di Niniwe seperti yang telah dinyatakan-Nya kepada orang-orang Israel.

Dalam konteks gereja, penginjilan bukan hanya berorientasi pada berapa banyak jiwa yang diperoleh, tetapi didasarkan pada keterbukaan Allah terhadap orang-orang yang belum percaya. Penginjilan bukan hanya upaya untuk memenangkan jumlah jiwa agar terdapat penambahan anggota gereja, tetapi karena menghidupi sikap Allah yang terbuka terhadap orang-orang yang belum percaya agar mereka pun mengalami anugerah Allah di dalam Yesus Kristus. Dengan nenghidupi keterbukaan Allah akan memotivasi para hamba Tuhan untuk hati misi dan tetap memiliki semangat penginjilan kepada mereka yang belum diselamatkan.

\section{Pemberitaan tentang Pertobatan}

Allah menyatakan malapetaka kepada orang-orang Niniwe tetapi Ia menerima pertobatan mereka, mengacu kepada dua implikasi praktis. Pertama, sikap tidak menolerir dosa yang dilakukan oleh orang-orang yang berada di luar Kristus dan hukuman yang akan mereka alami harus menjadi salah satu pendorong yang kuat bagi para hamba Tuhan untuk menyaksikan Kristus dan keselamatan di dalam-Nya. ${ }^{29}$ Kedua, pertobatan adalah cara untuk mengalami anugerah Allah.

Untuk itu, berita tentang pertobatan harusmenjadi salah satu penekanan utama dalam penginjilan, karena pertobatan adalah respon awal orang berdosa terhadap kasih Allah di dalam Yesus Kristus (bdg. Luk. 15:18, 20) ${ }^{30}$ dansebagai tindakan iman yang benar untuk mendapat keselamatan kekal dari Allah. ${ }^{31}$ Berita tentang pertobatan menjadi penting karena pertobatan adalah wujud perpalingan seseorang kepada Allah yang menyebabkannya membenci dosa, ${ }^{32}$ dan dengan pertobatan yang dialaminya menunjukkan bahwa ia menghargai pengorbanan Kristus di kayu salib untuk hidup memuliakan Allah. Dengan demikian, penginjilan tidak hanya terfokus pada proklamasi anugerah, tetapi juga penekanan tentang pertobatan sebagai wujud perpalingan seseorang dari hidup lamanya untuk hidup dalam hidup yang baru dalam Kristus Yesus.

\footnotetext{
${ }^{29}$ Hoekema, 123

${ }^{30}$ Derek Prince, Bertobat dan Percaya (Jakarta: Yayasan Pekabaran Injil Immanuel, 1992), 11.

${ }^{31}$ Ibid., 15.

${ }^{32}$ Harold M. Freligh, Delapan Tiang Keselamatan (Bandung: Kalam Hidup, n. d.), 16-17.
} 


\section{PENUTUP}

Kiranya dengan kajian ini, mereka yang seharusnya dipanggil Tuhan untuk pergi ke Niniwe (1:1-2), tetapi melarikan diri ke Tarsis (1:414), dan saat ini sedang berdoa dalam perut ikan besar dengan kebingungannya (Yun. 2:1-9), akan kembali kepada panggilannya, yaitu berbalik arah menuju ke Niniwe (3:1-2), untuk melaksanakan pelayanannya (3:4-9), karena Allah yang memanggil, walaupun Ia disebut Allah yang menyesal, tetapi Ia adalah Allah yang menyerukan anugerah, Allah menerima pertobatan, dan diakui dalam pemberitaan Perjanjian Lama. Sebagai Allah yang menyesal, Ia adalah Allah yang terbuka terhadap orang-orang yang belum diselamatkan; Ia adalah Allah yang berdaulat untuk melakukan yang terbaik bagi manusia; Ia adalah Allah yang Mahatahu yang mengantisipasi segala perubahan sikap hidup manusia di masa yang akan datang; Ia adalah Allah yang konsisten terhadap firman yang telah dinyatakan-Nya; dan Ia adalah Allah yang konsisten terhadap sifat-sifat-Nya, sebagai Allah yang penyayang dan pengasih serta panjang sabar dan berlimpah kasihs setia (4:2). 


\section{KEPUSTAKAAN}

\section{Alkitab}

Alkitab. Terjemahan Baru. Lembaga Alkitab Indonesia, 2008.

Biblia Hebraica Stutgartensia. Stuttgart: Deutsche Bibelgesellschaft, 1990.

Website

"How the Soveregin LORD God Prepares His Servants Isaiah 6:1-13" oleh Allen Ross, tersedia di http://www.bible.org/seriespage/howsovereign-lod-god-prepares-his-servants-isaiah-61-13 diakses pada tanggal 8 Januari 2012.

\section{Konkordansi}

Strong, James.Strong's Exhaustive Concordance of the Bible, Reference

Library Edition. Iowa Falls, Iowa: World Bible Publishers, n.d.

$$
\text { Jurnal }
$$

Chisholm, Robert B. "Does God Change His Mind?"Bibliotheca Sacra 152 (October-Desember 1995): 387-399.

Clines, David J. A., Philip R. Davies, and Andrew Mein (editors), Journal for the Study of the Old Testament Suplement Series 367. Sheffield: Sheffiel Academic Press, 2003.

Davies, Philip R., and David J. A. Clines. Journal for the Study of the Old Testament Supplement Series 144. Sheffield: Sheffield Academic Press, 1993

\section{Bibliografi}

Barth, C. Teologi Perjanjian Lama 4 (Jakarta: BPK Gunung Mulia, 1993.

Baxter, J. Sidlow.Menggali Isi Alkitab: Ayub s/d Maleakhi. Jakarta: Yayasan Komunikasi Bina Kasih, 1989.

Bolin, Thomas M. Freedom Beyond Forgiveness: The Book of Jonah Re-Examined. Sheffield: Sheffield Academic Press, 1997, 125.

Conn (editor), Harvie M.Reaching the Unreached: The Old-New Challenge. New Jersey: Presbyterian and Reformed Publishing Company, 1984.

Freligh, Harold M. Delapan Tiang Keselamatan. Bandung: Kalam Hidup, n.d.

Hill, Andrew E., \& John H. Walton. Survey Perjanjian Lama. Gandum Mas, 1996. 
Hoekema, Anthony A. Manusia: Ciptaan Menurut Gambar Allah. Surabaya: Momentum, 2003.

Keil, C. F., and F. Delitzsch. Biblical Commentary on The Old Testament. Grand Rapids, Michigan: Wm. B. Eerdmans Publishing Company, 1965.

Kramer, A. Th. Tafsiran Alkitab: Kitab Yunus. Jakartga: BPK Gunung Mulia, 1990.

McComiskey (editor), Thomas Edward. An Exegetical \& Expository Commentary Volume Two. Grand Rapids, Michigan: Baker Book House, 1993.

Prince, Derek. Bertobat dan Percaya. Jakarta: Yayasan Pekabaran Injil Immanuel, 1992.

Roy, Steven C. How Much Does God Foreknow? A Comprehensive Biblical Study. Downers Groves, Illinois: InterVarsity Press, 2006.

Ryrie, Charles.Teologi Dasar, buku 1. Yogyakarta: ANDI, 1992.

Sine, Tom. The Church In Respon to Human Need. Wheaton: Missions Advanced Research and Communication Center, 1983.

Ware, Bruce A. God's Lesser Glory: The Diminished God of Open Theism. Wheaton, Illinois: Crossway Books, 2000. 